\title{
Evaluation of the performance of HIV1 \& 2 one-step self- test kit for detection of HIV infection in whole human blood, serum or plasma samples.
}

\author{
Ya'aba $\mathrm{Y}^{1^{*}}$, Mohammed S.B ${ }^{1}$, Oladepo D.K ${ }^{1}$,Odama LE ${ }^{1}$,Ibrahim $\mathrm{K}^{1}$, \\ Izebe K.S ${ }^{1}$, Abdulrahim M.E ${ }^{1}$, Isu NR ${ }^{2}$, Onoja A.J ${ }^{3}$, Matur M.B $^{2}$, \\ Balogun O.O $\mathrm{O}^{4}$, Usoroh $\mathrm{M}^{1}$ and Inyang U.S ${ }^{1}$. \\ ${ }^{\prime}$ Department of Microbiology, Human Virology and Biotechnology. \\ National Institute for Pharmaceutical Research and Development (NIPRD) Idu-Abuja Nigeria. \\ ${ }^{2}$ Department of Biological Sciences, University of Abuja, Nigeria. \\ ${ }^{3}$ African Health Project, Abuja, Nigeria. \\ ${ }^{4}$ HIV Vaccine Trial Unit, Asokoro District Hospital, Abuja, Nigeria.
}

\begin{abstract}
Acquired immune deficiency syndrome (AIDS) is cause by Human Immunodeficiency Virus (HIV). It is an enveloped RNA virus belonging to the family of retroviruses responsible for destroying the human immune defence system. HIV antibody testing is critical for the diagnosis and counselling of HIV-infected persons, monitoring of trends in HIV prevalence, and evaluation of the effectiveness of HIV prevention programmes. Serological tests to detect antibodies to HIV became available in 1985, and since then more kits for this test are still being produced. A total of 500 positive and 500 negative samples were screened for HIV antibodies using Genie II HIV 1 \& 2(BIO-RAD; 3, Boulevard Raymond Poincare 92430 MARNES LA COQUETTE- FRANCE) and SeroCardTM HIV 1 \& 2 Rapid (Trinity Biotech PLC; IDA Business Park Bray Co. Wicklow Ireland.) and were further confirmed using New Lav Blot 1 western blot kit (BIO-RAD; 3, Boulevard Raymond Poincare 92430 MARNES LA COQUETTE- FRANCE). These samples were screened using the HIV1 \& 2 one-step self-test kit (Bremancos Diagnostics Inc. BDI with lot Number $0141503)$ to evaluate its performance. Whole blood, serum or plasma was used for the evaluation. Sensitivity of $99.2 \%$ and specificity of $99.8 \%$ were observed from the three sets of tests conducted while positive predictive value (PPV) of 0.99 and negative predictive value (NPV) of 0.99 each were calculated. The HIV $1 \& 2$ one-step-self test kit compared well with Genie II HIV 1 \& 2 kit and western blot kit for detecting HIV antibodies in patient's samples. Whole blood, plasma or serum can be used for the screening and easy for self test.
\end{abstract}

Keywords: HIV; AIDS; Genie II HIV I \&2; SeroCard" ${ }^{\text {TM }}$ HIV 1\&2 Rapid; New Lav Blot 1; HIV1 \& 2 one-step-self test.

\section{Introduction}

Infection with human immunodeficiency virus (HIV) has become pandemic since its first documentation in 1981 and is a major public health concern (8). HIV antibody testing is critical for the diagnosis and counselling of HIV-infected * Corresponding Author 
persons, the monitoring of trends in HIV prevalence and the evaluation of the effectiveness of HIV prevention programmes $(5,9)$. An unprecedented number of test systems for the detection of HIV antibodies are available. In some kits, improved sensitivity is frequently accompanied by a decreased specificity. This has been of particular concern with the introduction of test kits that detect all isotypes of antibodies, such as those based on antibody capture by antigens on a solid phase with labelled antigens as the detecting reagents $(4,7)$.

In resource-poor developing countries, the surveillance and diagnosis of HIV infection are major challenges (11). The conventional algorithm for HIV diagnostic testing consists of screening with enzyme immunoassays followed by confirmation with a Western blot test. Moreover, a double enzyme-linked immunosorbent assay (ELISA) without Western blotting has been accepted as the customary screening assay for HIV infection (13). Because of the high cost of the Western blot test, it has not been affordable in a number of laboratories in developing countries (1). Rapid screening for HIV infection performed on-site with tests that do not require expensive laboratory infrastructure or highly skilled personnel helps with the diagnosis of patients (10).

Serological diagnosis and confirmation are some methods of identifying human immunodeficiency virus (HIV) in an infected patient. A well established, reference gold standard test must be available to the laboratory, the results of which should correlate with the actual status of the patient (2).

Essentially, any repeatedly positive result by Enzyme-Linked Immuno Sorbent Assay (ELISA) or with another rapid screening method and with different flow characteristics is acceptable as true positive according to the CDC guidelines on HIV antibodies testing. However in low risk groups Western blot is advisable (6).

Since the diagnosis of human immunodeficiency virus (HIV) infection is important for patient management and prevention of new infections and a number of test kits by different manufacturers are available in Nigerian markets for detection of these antibodies, this study was designed to evaluate and to find out the reaction profile of HIV 1 \& 2 one-step self-test kit for dictation of HIV infection in human whole blood and serum/plasma samples.

\section{Materials and Methods}

This study was carried out at the Department of Microbiology, Human Virology and Biotechnology of National Institute for Pharmaceutical Research and Development (NIPRD) Idu-Abuja. It is a referral centre for voluntary counselling and testing (VCT) in Abuja, Nigeria. A total of 1000 specimens (Whole blood, plasma or serum) were collected from VCT clients and were tested using Genie II HIV-1/ HIV-2(BIO-RAD; 3, Boulevard Raymond Poincare 92430 MARNES LA COQUETTE- FRANCE) and Sero - Card ${ }^{\mathrm{TM}}$ HIV $1 \& 2$ Rapid (Trinity Biotech 
PLC; IDA Business Park Bray Co. Wicklow Ireland). These specimens were further confirmed using New Lav Blot 1 Western blot kits (BIO-RAD; 3, Boulevard Raymond Poincare 92430 MARNES LA COQUETTE- FRANCE) according to manufacturer's instructions. The positive western blot was considered by the presence of at least two of the three bands representing the envelope bands gp160, gp120, and gp41 and gag gene product p24 of HIV-1; and absence of all the bands except control band was considered as negative test respectively (3). Five hundred (500) positive and five hundred (500) negative samples that were confirmed using western blot kit (Gold standard) were used to evaluate the performance of HIV1 \& 2 one- step self-test kit (Bremancos Diagnostics Inc. BDI with lot Number 0141503). The manufacturer's instruction recommended the use of whole blood for the HIV-1/2 one-step self-test kit. Therefore the samples used for the evaluation were stored as whole blood until the evaluation was done.

One (1) drop of whole blood was transfer using the plastic pipette into the sample well. Six (6) drops of buffer in a plastic vial was added to sample well and the result was read 20 minutes after addition of the buffer.

\section{Results}

The study shows that HIV $1 \& 2$ one-step self-test kit has a sensitivity of $99.2 \%$ and specificity of $99.8 \%$. The positive predictive value (PPV) of 0.99 and negative predictive value (NPV) of 0.99 each was also observed and calculated Table 1.

Sensitivity $=$ True Positve $/$ (false negatives + true positives $)$

$$
\begin{aligned}
& =499 /(499+4) * 100 \\
& =99.2 \%
\end{aligned}
$$

Specificity $=$ True Negatives $/$ (False Positives + True Negatives $)$

$$
=496 /(496+1) * 100
$$

$$
=99.8 \%
$$

Positive Predictive Value $(\mathrm{PPV})=$ True Positives $/($ True Positive + False Positive $)$

$$
\begin{aligned}
& =499 /(499+1) \\
& =0.99
\end{aligned}
$$

Negative Predictive Value $(\mathrm{NPV})=$ True Negatives $/($ True Negatives + False Negatives)

$$
\begin{aligned}
& =496 /(496+4) \\
& =0.99
\end{aligned}
$$

\section{Discussion and Conclusion}

Diagnosis of human immunodeficiency virus (HIV) infection is important for patient management. Therefore, development, introduction, and use of the newly arriving HIV antibody detection assays are dynamic process. It is essential that these assays are thoroughly evaluated before use at different levels and conditions. 
Table 1: Performance of kits with known Specimens.

\begin{tabular}{|l|l|l|l|}
\hline & \multicolumn{3}{|l|}{ No. of specimen identified correctly by: } \\
\hline $\begin{array}{l}\text { Specimen (Total } \\
\text { number) }\end{array}$ & $\begin{array}{l}\text { Sero - Card" HIV } \\
\text { 1/2 Rapid. }\end{array}$ & $\begin{array}{l}\text { Genie 11 HIV -1/ } \\
\text { HIV-2. }\end{array}$ & $\begin{array}{l}\text { HIV1/2 one-step } \\
\text { self-test kit. }\end{array}$ \\
\hline $\begin{array}{l}\text { Western blot } \\
\text { comfirmed HIV } \\
\text { positive (n=500) }\end{array}$ & 500 & 500 & 499 \\
\hline $\begin{array}{l}\text { Western blot } \\
\text { comfirmed HIV } \\
\text { negative (n=500) }\end{array}$ & 500 & 500 & 496 \\
\hline
\end{tabular}

The sensitivity, specificity, predictive values, false positive ratio, ease of performance and interpretation, suitability for use in small collection centres and the test efficiency need to be evaluated using different combinations of assays (12)

The HIV $1 \& 2$ one-step self-test kit compared well with Genie II HIV1 \& 2 kit and western blot for detecting HIV antibodies in patients' samples. This is due to its sensitivity of $99.2 \%$, specificity of $99.8 \%$, positive predictive value (PPV) of 0.99 and negative predictive value (NPV) of 0.99 . This kit may be good in the blood transfusion section, as it does not throw away a positive result as negative. Another advantage is that whole blood, plasma or serum can be used to detect antibodies using this kit, therefore easy for self test, field work that requires large number of samples, and point-of- care rapid testing.

There are many HIV screening kits on the Nigerian today. One wonders which one is good and which is not. It is very important that the Federal Ministry of Health (FMOH) do quality control evaluation of these HIV screening kits that are being imported into the country. And adequate information as to their efficiencies should be given to the public, since laboratory investigations are to help in diagnosis of HIV infection and not to misdiagnose and increase the rate of HIV infection in Nigeria.

Finally, in order to excel in our fight against this dreaded disease AIDS, the Nigeria Government, non-Governmental organizations (NGO's), researchers and medical personnel should not only pay attention to public awareness about HIV/AIDS but should also look into HIV kits evaluation.

\section{References}

1. Asihene, P. J., R. L. Kline, M. W. Moss, A. V. Carella, and T. C. Quinn (1994): Evaluation of rapid test for detection of antibody to human immunodeficiency virus type 1 and type $2 . J$. Clin. Microbiol.32:1341-1342.

2. Baveja U, Chattopadhya D and Aggarwal S (1999): Evaluation of HIV kits and preparation 
of serum panels, Chapter 11. In: HIV testing manual, laboratory diagnosis, biosafety and quality control. National Institute of Communicable Diseases and National AIDS Control Organisation, Ministry of Health and Family Welfare, Govt. of India New Delhi, 107-113.

3. Edward B and Susan WB (1995): Human Immunodeficiency Virus. Chapter 97 In: Manual of Clinical Microbiology, 6th ed. Murray PR, Baron ES, Pfaller MA, Tenover FC, Yolken RH, Eds. (ASM Press, Washington DC) Pg 1098-1114.

4. Gonzalez, L., R. W. Boyle, M. Zhang, J. Castillo, S. Whittier, P. Della-Latta, L. M. Clarke, J. R. George, X. Fang, J. G. Wang, B. Hosein, and C. Y. Wang (1997): Synthetic-peptide-based enzyme-linked immunosorbent assay for screening human serum or plasma for antibodies to human immunodeficiency virus type 1 and type 2. Clin. Diagn. Lab. Immunol. 4:598-603.

5. Kannangai, R., S. Ramalingam, S. Pradeepkumar, K. Damodharan, and G. Sridharan (2000): Hospital- based evaluation of two rapid human immunodeficiency virus antibody screening tests. J. Clin. Microbiol. 38:3445-3447.

6. Kline RL, McNairn D, Holodniy M, Mole L, Margolis D, Blattner W and Quinn T C (1996): Evaluation of Chiron HIV-1/HIV-2 recombinant Immunoblots assay. J Clin Microbiol 34:2650-2653.

7. Matter, L., and D. Germann (1995): Detection of human immunodeficiency virus (HIV) type 1 antibodies by new automated microparticle enzyme immunoassay for HIV types 1 and 2.J. Clin. Microbiol.33:2338-2341.

8. National AIDS Control Organization (2004): An overview of the spread and prevalence of HIV/AIDS in India. NACO, Ministry of Health and Family Welfare, Government of India.

9. Nkengasong, J. N., C. Maurice, S. Koblavi, M. Kalou, D. Yavo, M. Maran, C. Bile, K. N'guessan, J. Kouadio, S. Bony, S. Z. Wiktor, and A. E. Greenberg (1999): Evaluation of HIV serial and parallel serologic testing algorithms in Abidjan, Côte d'Ivoire. AIDS 13:109117

10. Palmer, C. J., J. M. Dubon, E. Koenig, E. Perez, A. Ager, D. Jayaweera, R. R. Cuadrado, A. Rivera, A. Rubido, and D. A. Palmer (1999): Field evaluation of the Determine rapid human immunodeficiency virus diagnostic test in Honduras and the Dominican Republic. J. Clin. Microbiol.37:3698-3700.

11. Ribeiro-Rodrigues, R., L. F. da Silva Pinto Neto, C. B. Cunha, V. P. Cabral, and R. Dietze (2003): Performance characteristics of a rapid new immunochromatographic test for detection of antibodies to human immunodeficiency virus. Clin. Diagn. Lab. Immunol. 10:303-307.

12. Tegbaru B, Meles H, Fisseha B, Mekonnen Y and Haile H (1999): Evaluation of five commercial assays for detecting HIV 1 and 2 antibodies, Addis Ababa Ethiopia. $J$ Health $\operatorname{Dev} 13(3): 175-180$.

13. UNAIDS/WHO Working Group on Global HIV/AIDS/STI Surveillance (2001): Guidelines for using HIV testing technologies in surveillance: selection, evaluation, and implementation.UNAIDS and WHOHIV testing strategies. StrategyII. $\mathrm{WHO} / \mathrm{CDS} / \mathrm{CSR} / \mathrm{EDC} / 2001.16 \mathrm{UNAIDS} / 01.22 \mathrm{E}: 23$

14. CDC Recommendations (1989): Interpretation and use of the Western blot assay for serodiagnosis of Human immunodeficiency virus type 1 infections. MMWR 38:1-7 